\title{
Photochemistry of Styrene Oxide: A Triplet Pathway in the Singlet Excitation of a Monoaryl Oxirane
}

\author{
Benny E. Aney ${ }^{1}$, Heiko Ihmels ${ }^{2}$, Rick C. White ${ }^{1}$ \\ ${ }^{1}$ Department of Chemistry, Sam Houston State University, Huntsville, TX, USA \\ ${ }^{2}$ University of Siegen, Siegen, Germany \\ Email: chm_rcw@shsu.edu
}

How to cite this paper: Aney, B.E., Ihmels, H. and White, R.C. (2017) Photochemistry of Styrene Oxide: A Triplet Pathway in the Singlet Excitation of a Monoaryl Oxirane. International Journal of Organic Chemistry, 7, 263-268.

https://doi.org/10.4236/ijoc.2017.73020

Received: July 31, 2017

Accepted: August 29, 2017

Published: September 1, 2017

Copyright $\odot 2017$ by authors and Scientific Research Publishing Inc. This work is licensed under the Creative Commons Attribution International License (CC BY 4.0).

http://creativecommons.org/licenses/by/4.0/

\begin{abstract}
Direct photolysis and quenching experiments with styrene oxide support the existence of an efficient triplet photochemical pathway to benzyl radical formation. Similar photolytic behavior for styrene glycol carbonate strongly supports the 1,3-diradical, resulting from the scission of the benzylic C-O bond, as the geometric source of the triplet pathway. Primary photoproducts were determined by both NMR and HPLC analysis and we observed that toluene and bibenzyl were both primary photoproducts, not secondary photoproducts.
\end{abstract}

\section{Keywords}

Photochemistry, Oxiranes, Cyclic Carbonate Esters, Mechanisms

\section{Introduction}

Unsubstituted and aryl substituted oxiranes have been described as undergoing benzylic carbon-oxygen bond cleavage [1] [2] rather than benzylic carbon bond cleavage resulting in carbonyl ylid formation [3]. Evidence for the formation of the latter was provided by trapping of the subsequently formed carbenes. In 1966, Kristinnson and Griffin [4] [5] [6] [7] [8] reported that the photolysis of styrene oxide (1) in benzene induces the cleavage of the benzylic oxiranyl carbon bond to give a 1,3-diradical (1a) which undergoes a hydrogen migration to generate phenyl acetaldehyde (2). Subsequent photo-decarbonylation of 2 gave bibenzyl (3) as the only reported secondary photoproduct shown in Scheme 1. Griffin also noted in a later report that benzyl radicals were formed 5 - 6 times faster in the photolysis of 1 than from 2. 


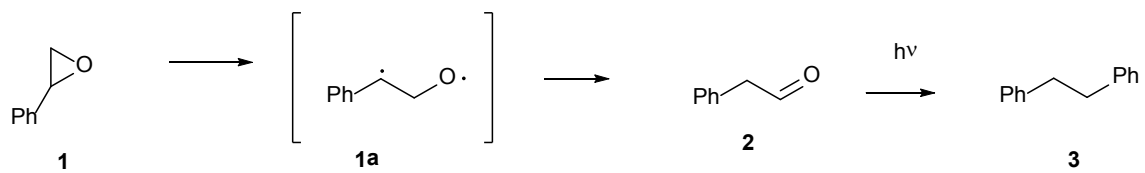

Scheme 1. Proposed mechanism of the photoreaction of styrene oxide (1).

We also reported on the triplet decarbonylation pathway in the photochemistry of 1, 2-dihydroxynaphthalene oxide [9] in which indane (5) is formed as a primary photoproduct, shown in Scheme 2.

The singlet dissociation of the oxirane (sensitized irradiation revealed no reaction) was followed by a triplet state decarbonylation leading to 5 as a primary photoproduct.

\section{Results and Discussion}

Irradiation of $1 \mathrm{a}, \mathrm{b}$ ( $254 \mathrm{~nm}, 0.05 \mathrm{M}$ on acetonitrile) gave 2, 3 and toluene (6) as products by NMR spectroscopy [10]. Scheme 3 shows that irradiation of 1 and 7 both gave 2, 3 and 6 .

The formation of 3 and $\mathbf{6}$ was observed by GC/MS, HPLC and ${ }^{1} \mathrm{H}$ NMR spectroscopic analyses at short irradiation times ( $<5 \%$ conversion) suggesting these two compounds are primary photoproducts. The irradiation $\left(254 \mathrm{~nm}, \mathrm{CH}_{3} \mathrm{CN}\right)$ of $1(0.05 \mathrm{M})$ in the presence of a triplet quencher isoprene $(0.015 \mathrm{M})$ exhibited a $69 \%$ reduction in the early formation of both 3 and 6 in the early stages of the photoreaction, which shows a triplet pathway for the formation 3 and 6 as primary photoproducts. Quenching of the triplet most likely occurs prior to the dissociation of the benzylic $\mathrm{C}-\mathrm{C}$ bond as indicated by the reduction of $\mathbf{3}$ and the absence of any carbonyl ylid derived products.

Attempts to form 3 and 7 by means of a triplet-sensitized photolysis of 1 were unsuccessful as the initial ring opening is a singlet state process although we have shown that dihydronaphthalene oxide undergoes photochemical reaction to produce indan-1-carbaldehyde through a singlet process and that the starting epoxide sensitizes the decarbonylation of the aldehyde to produce indane. Here, we have 1 sensitizing the conversion of $\mathbf{2}$ to 3 and $\mathbf{6}$. Formation of 6 was monitored by HPLC analysis of the reaction (Figure 1). The upward curvature at longer reaction times shows that 6 originates from two sources: an early relatively inefficiently source and a later more efficient source which correlates with increasing formation of 2.

To gain more insight into these separate reaction pathways, he corresponding quantum yields were determined [10] $(\Phi 1 \rightarrow 2,=0.52, \Phi 1 \rightarrow 6=0.47, \Phi 2 \rightarrow 6=$ 0.21 . If 6 were strictly derived from 2 , its quantum yield of formation $(\Phi 1 \rightarrow 6$ would be negligible under the condition of quantum yield measurements $(<5 \%$ conversion, but this was not the case $(\Phi 1 \rightarrow 6=0.047)$. A plot of the formation of 2 versus time (Figure 2) showed an apparent steady state rate of formation with a delayed upward curve as the concentration of $\mathbf{2}$ increased. 


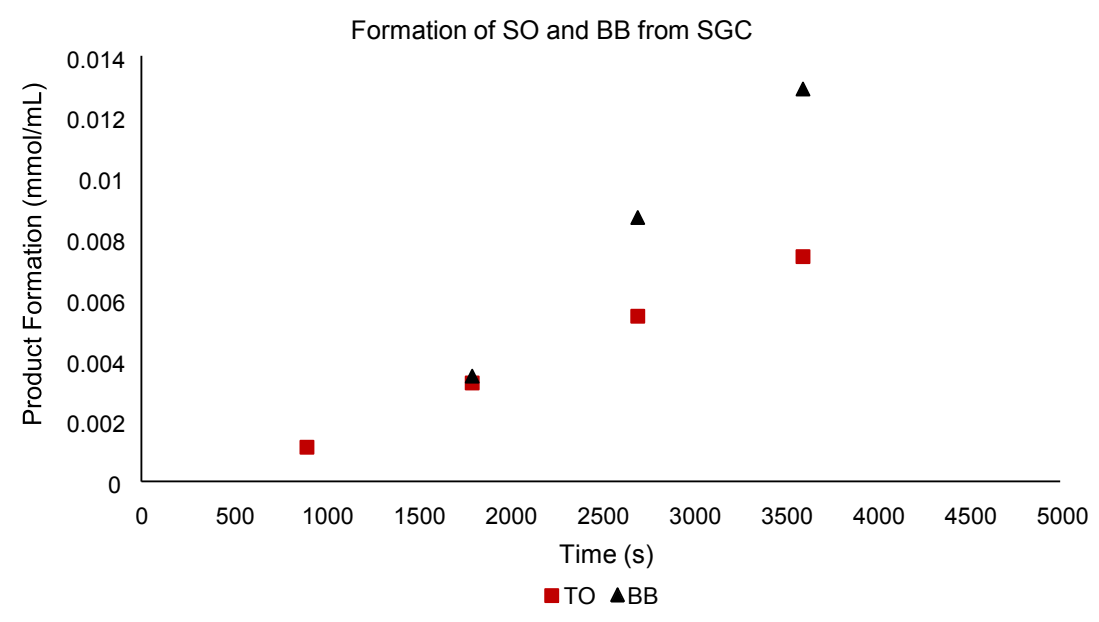

Figure 1. Formation of 3 (diamonds) and 6 (squares) in the photolysis of SGC.

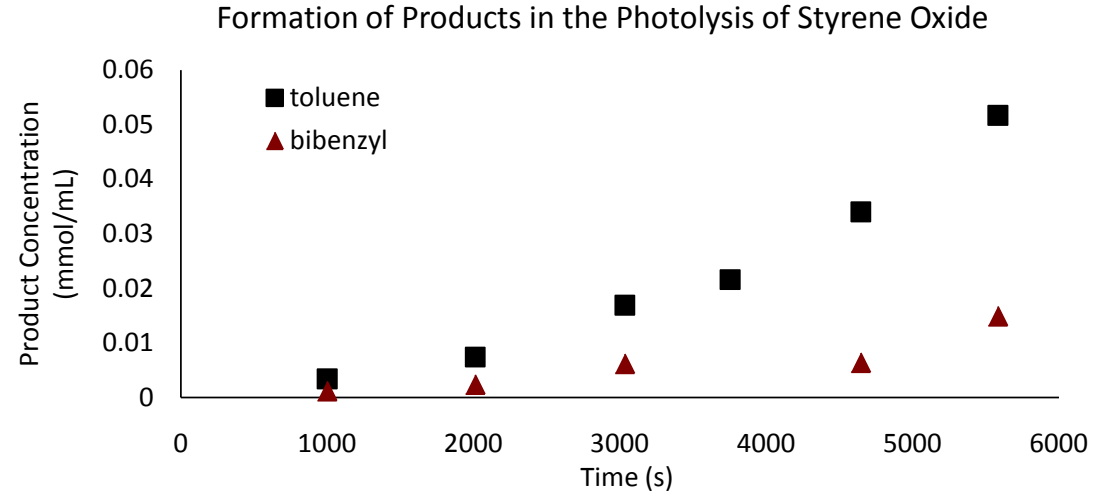

Figure 2. Formation of products in the photolysis of 1.

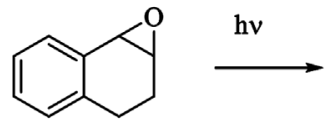

5<smiles>c1ccc2c(c1)CCC2</smiles><smiles>OC1CCc2ccccc2C1</smiles>

4a<smiles>O=CCCc1ccccc1I</smiles>

H abstraction

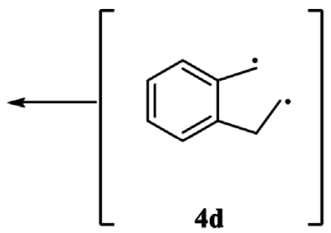

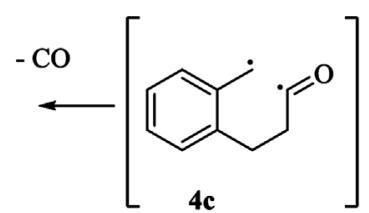

Scheme 2. Postulated mechanism for the photolysis of 4 .
$\overbrace{}^{\mathrm{R}} \mathrm{O}$

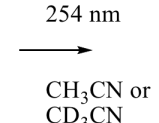<smiles>[X]C(=O)C([X])c1ccccc1</smiles><smiles>C1CCCC1</smiles><smiles>[X]C(P)C([X])c1ccccc1</smiles>

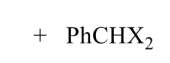

$254 \mathrm{~nm}$ $\mathrm{CD}_{3} \mathrm{CN}$

1a: $R=H$
1b $R=D$

$$
\begin{aligned}
& \text { 2a: } R=H \\
& \text { 2b: } R=D
\end{aligned}
$$$$
\begin{gathered}
\text { 3a: } \mathbf{R}=\mathbf{H} \\
\text { 3b: } \mathbf{R}=\mathbf{D}
\end{gathered}
$$$$
\text { 6a: } X=H
$$$$
\text { 6b: } X=D
$$

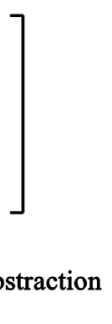

Scheme 3. Photoreaction of 1 in deuterated solvents. 
We also monitored the formation of 3 in the reaction of 1 (Figure 1). As observed for $\mathbf{6}$, the formation of $\mathbf{3}$ showed a steady significant rate of formation that increased dramatically later as the reaction progressed due to its production from two sources, 1 and 2.

Styrene glycol carbonate (7) reportedly mimics the photochemistry of 1 [11] with the photo-induced extrusion of $\mathrm{CO}_{2}$ to generate the same diradical, (1a) as derived from 1 (Scheme 1). Analysis of the early formation of $\mathbf{3}$ and $\mathbf{6}$ during the photolysis of 7 by HPLC showed that both were minor primary photoproducts (Scheme 3).

This process is similar for the behavior observed for 1 supporting the position that the generation of the additional benzyl radicals occurred after the formation of 1a rather than via a separate pathway from the starting oxirane as seen in Figure 1 and outlined in Scheme 4.

Photolyisis of 1 and 7 (Scheme 5) were carried out in cyclohexene/acetonitrile (20:80 v/v), 1H NMR spectroscopic and GC/MS analysis of the photolysate revealed 3-benzylcyclohexene (8) and 3,3'-bicyclohexenyl (9) among the photoproducts, but no 7-phenylnorcarane was detected [10]. An earlier report on the photolysis of phenyl diazomethane with cyclohexene showed that the singlet/triplet states of phenylcarbene rapidly equilibrate to give mainly norcarane derivatives with $2 \%$ - $5 \%$ insertion into the allylic $\mathrm{C}-\mathrm{H}$ bond leading to 8 [12].

Similarly, photolysis of $\beta, \beta$-dideuterio styrene oxide in the presence of cyclohexene produced $8 \mathrm{~d}, 3 \mathrm{~b}$, and 9 .

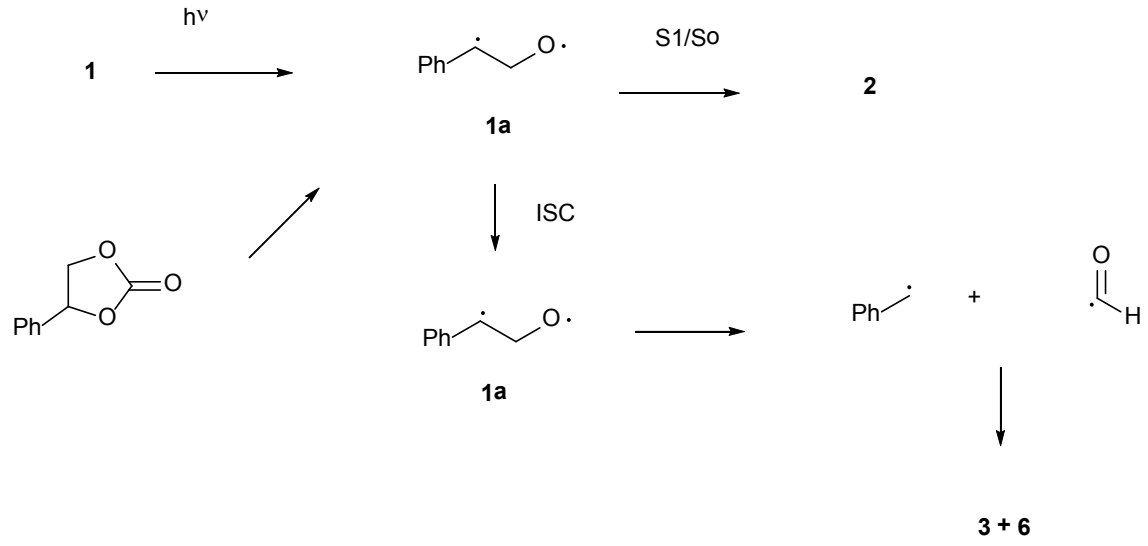

Scheme 4. Outline of Photochemical pathways for 3 and 6.
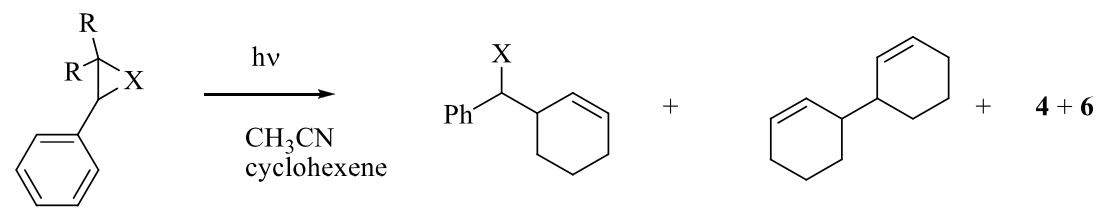

$$
\begin{aligned}
& \text { 1: } \mathbf{X}=\mathbf{O}, \mathbf{R}=\mathbf{H} \\
& \text { 1-d } \mathrm{d}=\mathrm{X}, \mathrm{R}=\mathrm{D} \\
& \text { 7: }=\mathrm{O}(\mathrm{CO}) \mathrm{O}, \mathrm{R}=\mathrm{H}
\end{aligned}
$$

$$
\text { 8: } \mathbf{R}=\mathbf{H}
$$$$
9
$$

Scheme 5. Photolysis of 1, its dideuterio derivative, and 7 in the presence of cyclohexene. 


\section{Experiment}

Styrene oxide (SO) was purchased commercially and stirred over semicarbazide hydrochloride before being distilled under reduced pressure. Styrene glycol carbonate (SGC) was prepared as described previously [9]. NMR data were recorded with a $300 \mathrm{MHz}$ instrument and product amounts were determined by HPLC using a 60:40 acetonitrile/water mobile phase with propylbenzene as an internal standard. Photochemical reactions were carried out with a Rayonet Photochemical Reactor equipped with either eight RPR 2454 lamps (direct irradiation) or 8 RPR 3000 lamps (sensitized irradiations).

\section{Photochemical Studies of SO and SGC}

Direct irradiations were carried out on $5 \mathrm{~mL}$ samples ( $0.05 \mathrm{M}$ in acetonitrile) after outgassing with argon for 15 minutes. Sensitized irradiations were carried out in acetone solution $(0.05 \mathrm{M})$ after outgassing for 15 minutes with argon.

Reactions in the presence of cyclohexene were carried out with $40 \mathrm{mg}$ of SO and $100 \mathrm{mg}$ of cyclohexene in acetonitrile after outgassing for 15 minutes with argon. Quenching studies were carried out using SO and isoprene under conditions such that SO absorbed $>99 \%$ of the incident light.

Analyses of the reaction by GC/MS. GC/MS conditions were such that the inject was set at $50^{\circ} \mathrm{C}$ and the data collection set at 1 minute to capture data for tolu-ene.

\section{Limitations of the Study}

In these reactions, we find that the reaction works well when the process involves a simple 1,3-diradical. For example, the photolysis of 2, 2-dimethyl-3phenyloxirane is not reactive due to the non-reactivity of the oxirane due to geometric restraints [13]. We find that the same process holds true for spiro(fluorene-9,2'-oxirane).<smiles>c1ccc2c(c1)-c1ccccc1C21CO1</smiles>

10

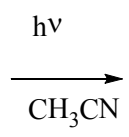

11

\section{Acknowledgements}

Support for this work by the Welch Foundation (Grant x-0011) is greatly appreciated.

\section{References}

[1] Gomer, R. and Noyes Jr., W.A. (1950) Photochemical Studies. XLII. Ethylene Oxide. Journal of the American Chemical Society, 72, 101-108.

https://doi.org/10.1021/ja01157a029 
[2] Kawasaki, M., Ibuki, T., Iwasaki, M. and Takezaki, Y. (1973) Vacuum-Ultraviolet Photolysis of Ethylene Oxide. Journal of Chemical Physics, 59, 2076. https://doi.org/10.1063/1.1680294

[3] Kristinsson, H. and Griffin, G.W. (1966) Photochemistry of Phenyloxiranes. II. New Precursors for Phenylcarbene. Journal of the American Chemical Society, 88, 1579-1580. https://doi.org/10.1021/ja00959a065

[4] Becker, R.S., Bost, R.O., Kolc, J., Bertionere, N.R., Smith, R.L. and Griffin, G.W. (1970) Spectroscopy and Photochemistry of Aryloxiranes. Journal of the American Chemical Society, 92, 1302-1311. https://doi.org/10.1021/ja00708a033

[5] Trozzola, A.M., Yager, W.A., Griffin, G.W., Kristinsson, H. and Sarkar, I. (1967) Direct Evidence for the Formation of Diphenylmethylene in the Photolysis of Triphenyl- and Tetraphenyloxirane. Journal of the American Chemical Society, 89, 3357-3358. https://doi.org/10.1021/ja00989a051

[6] Petrellis, P.C., Dietrich, H., Meyer, E. and Griffin, G.W. (1967) Photofragmentation of Epoxides. IV. Precursors Phenylcyanocarbene. Journal of the American Chemical Society, 89, 1967-1969. https://doi.org/10.1021/ja00984a047

[7] Griffin, G.W. (1971) Generation of Carbenes by Photochemical Cycloelimination. Angewandte Chemie International Edition in English, 10, 537-547. https://doi.org/10.1002/anie.197105371

[8] Kristinnson, H. and Griffin, G.W. (1965) Formation of Phenylcarbenes by Photolysis of Phenyloxiranes. Angewandte Chemie International Edition in English, 4, 868. https://doi.org/10.1002/anie.196508682

[9] White, R.C., White, K.M. and Arney Jr., B.E. (2006) Photochemistry of 1,2-Dihydronaphthalene Oxide: Concurrent Triplet and Singlet Processes via Singlet Excitation. Journal of Organic Chemistry, 71, 8173-8177. https://doi.org/10.1021/jo0614184

[10] The Oxiranes and Carbonates ( 0.05M) Were Dissolved in Acetonitrile, Placed in Quartz Tubes, Sparged with Argon, and Irradiated in a Rayonet Reactor Equipped with 8 RPR 2537 Lamps.

[11] White, R.C. and Ma, S. (1988) Photochemistry of 4-Phenyl-1,3-Dioxolan-2-One”. Journal of Heterocyclic Chemistry, 1987, 1203 and References Found Therein; White, R.C.

[12] Savino, T.G., Kanakarajan, K. and Platz, M.S. (1986) Unusual Temperature-Dependent Isotope Effects in the Reactions of Phenylcarbene with Cyclohexene and Cyclohexane. Journal of Organic Chemistry, 51, 1305-1309. https://doi.org/10.1021/jo00358a027

[13] Linder, S., White, K., Palmer, M., Arney, B. and White, R.C. (2002) Geometric Requirements for the Photolysis of Aryloxiranes and Cyclic Carbonate Esters. Tetrahedron Letters, 43, 1169-1170. https://doi.org/10.1016/S0040-4039(01)02392-9 
Submit or recommend next manuscript to SCIRP and we will provide best service for you:

Accepting pre-submission inquiries through Email, Facebook, LinkedIn, Twitter, etc. A wide selection of journals (inclusive of 9 subjects, more than 200 journals)

Providing 24-hour high-quality service

User-friendly online submission system

Fair and swift peer-review system

Efficient typesetting and proofreading procedure

Display of the result of downloads and visits, as well as the number of cited articles Maximum dissemination of your research work

Submit your manuscript at: http://papersubmission.scirp.org/

Or contact ijoc@scirp.org 